\title{
Role of Archaeal HerA Protein in the Biology of the Bacterium Thermus thermophilus
}

\author{
Alba Blesa ${ }^{1}$, Nieves G. Quintans ${ }^{1}$, Ignacio Baquedano ${ }^{1}$, Carlos P. Mata ${ }^{2}$, José R. Castón ${ }^{2}$ \\ and José Berenguer ${ }^{1, *}$ \\ 1 Centro de Biología Molecular Severo Ochoa, Universidad Autónoma de Madrid-Consejo Superior de \\ Investigaciones Científicas, Calle Nicolás Cabrera 1, Madrid 28049, Spain; ablesa@cbm.csic.es (A.B.); \\ ngquintans@cbm.csic.es (N.G.Q.); ibaquedano@cbm.csic.es (I.B.) \\ 2 Department of Structure of Macromolecules, Centro Nacional de Biotecnología (CNB), \\ Consejo Superior de Investigaciones Científicas (CSIC), Cantoblanco, Madrid 28049, Spain; \\ cperez@cnb.csic.es (C.P.M.); jrcaston@cnb.csic.es (J.R.C.) \\ * Correspondence: jberenguer@cbm.csic.es; Tel.: +34-91-196-4498
}

Academic Editors: John Jones and Etienne G.J. Danchin

Received: 15 March 2017; Accepted: 24 April 2017; Published: 27 April 2017

\begin{abstract}
Intense gene flux between prokaryotes result in high percentage of archaeal genes in the genome of the thermophilic bacteria Thermus spp. Among these archaeal genes a homolog to the Sulfolobus spp. HerA protein appears in all of the Thermus spp. strains so far sequenced (HepA). The role of HepA in Thermus thermophilus HB27 has been analyzed using deletion mutants, and its structure resolved at low resolution by electron microscopy. Recombinant HepA shows DNA-dependent ATPase activity and its structure revealed a double ring, conically-shaped hexamer with an upper diameter of $150 \AA$ and a bottom module of $95 \AA$. A central pore was detected in the structure that ranges from $13 \AA$ at one extreme, to $30 \AA$ at the other. Mutants lacking HepA show defective natural competence and DNA donation capability in a conjugation-like process termed "transjugation", and also high sensitivity to UV and dramatic sensitivity to high temperatures. These data support that acquisition of an ancestral archaeal HerA has been fundamental for the adaptation of Thermus spp. to high temperatures.
\end{abstract}

Keywords: HerA; Thermus; DNA repair; transjugation; transformation; lateral gene transfer; hexameric ATPase

\section{Introduction}

Phylogenetic analysis based on the use of 16sRNA and in concatenated analysis of up to 30 ribosomal protein genes, support that the genus Thermus belongs to one of the most ancient groups of bacteria, which also includes the radio-resistant mesophilic genera Deinococcus [1,2]. Further whole genome comparisons strongly support the close relationship between both genera, with a common ancestor likely of moderate thermophilic character that already contained genes transferred from thermophilic archaea and bacteria [3]. Further adaptation of the common ancestor of the clade to different extreme conditions required gene gain in the case of Deinococcus, which allowed its extreme resistance to radiation, and a balance between gene losses and gains in the case of adaptation to extreme temperatures for Thermus species (spp.). In the latter case, several genes have been acquired from thermophilic archaea, including many of them likely involved in DNA maintenance, DNA repair, and CRISPR-Cas defense systems [3]. Many of these archaeal genes are located in a megaplasmid (pTT27) present in most Thermus spp. which constitutes a very plastic element where most of the differences between the Thermus species concentrate [4]. 
A homolog of the HerA helicase is found among the genes of archaeal origin likely present in the common ancestor of the Thermus-Deinococcus clade [5]. In thermophilic archaea, the helicase HerA is an essential enzyme encoded in a UV-induced operon that includes a NurA nuclease and DNA repair protein homologs to the eukaryotic Mre11 and Rad50 proteins. These eukaryotic Mre11 and Rad50 counterparts recognize and bind to double-stranded breaks (DSB) before recruiting the nuclease and helicase components required to generate a 3' single-stranded DNA overhang, which is further recognized by the Rad51 recombinase to initiate strand invasion in homologous recombination (HR). Thus, it is assumed that a similar role is played in archaea by HerA, NurA, and Mre11 and Rad50 homologs, which are co-translated from a polycistronic mRNA. In this context, a model for the concerted action of HerA and NurA has been recently proposed based on the crystal structure of the Sulfolobus solfataricus proteins in which the HerA hexamer pushes double-stranded DNA through its central channel towards a NurA dimer, where DNA degradation takes place [6].

The role of the archaeal HerA and NurA proteins has also been studied in Deinococcus radiodurans [7]. In this bacterium, the absence of nurA, herA, or both results in defective cell proliferation and a 10-fold reduced intermolecular recombination, but without apparent affection to the high radio-resistance shown by this organism. Two hybrid assays supported, for D. radiodurans, the existence of interaction between both proteins through the N-terminal HAS domain of HerA, with such interaction stimulating each other activity (ATPase for HerA and nuclease for NurA).

In all of the Thermus spp. so far sequenced, an archaeal HerA homologue is encoded in the chromosome. We will call this protein helicase protein A (HepA) hereafter to avoid confusion with the extensively studied dead-box RNA helicase Hera [8]. Here, we have investigated HepA both at the level of overall protein structure, through electron microscopy and image reconstruction, and also in the biology of T. thermophilus. Our data show that HepA plays a relevant role in adaptation to high temperatures as its absence severely affects UV resistance and impairs growth at high temperatures. Affection to DNA mobilization processes is also reported.

\section{Materials and Methods}

\subsection{Strains and Growth Conditions}

Bacterial strains and derived mutants are described in Table 1. T. thermophilus was routinely grown at $60{ }^{\circ} \mathrm{C}$ in Erlenmeyer flasks filled up to $1 / 5$ of their capacity with Thermus broth (TB) under rotational shaking (150 rpm) [9]. Escherichia coli strains DH5 $\alpha$ and BL21 (DE3) were used for cloning purposes and recombinant protein expression, respectively. Both strains and derivatives carrying plasmids were grown at $37^{\circ} \mathrm{C}$ in liquid or solid LB media, with kanamycin $\left(\mathrm{Km}, 30 \mathrm{mg} \cdot \mathrm{L}^{-1}\right)$, ampicillin (Am, $\left.100 \mathrm{mg} \cdot \mathrm{L}^{-1}\right)$, or hygromycin B $\left(\mathrm{Hyg}, 100 \mathrm{mg} \cdot \mathrm{L}^{-1}\right)$, as required.

Table 1. Strains used in this work.

\begin{tabular}{|c|c|c|}
\hline Strain & Genotype & Source \\
\hline E. coli $\mathrm{DH} 5 \alpha$ & supE44 $\Delta$ lacU169 ( $\$ 80$ lacZ $\Delta M 15)$ hsdR17, recA1, endA1, gyrA96, thi-1 relA1 & [10] \\
\hline E. coli BL21 (DE3) & $F^{-}$ompT gal dcm lon HsdSB $\left(\mathrm{r}_{\mathrm{B}}^{-} \mathrm{m}_{\mathrm{B}}^{-}\right) \lambda(\mathrm{DE} 3$ [lacI lacUV5-T7 gene 1 ind1 sam7 nin5]) & [11] \\
\hline T. thermophilus HB27 & ATCC BAA-163/DSM7039 & Y. Koyama \\
\hline T. thermophilus NAR1 & [pTT27::nar] & [12] \\
\hline T. thermophilus HB8 & ATCC 27634 & Y. Koyama \\
\hline T. thermophilus $\mathrm{HB} 27^{\mathrm{EC}}$ & HB27 ago::agoISTth7 & [13] \\
\hline T. thermophilus $\mathrm{HB} 27^{\mathrm{Cm}}$ & & This work \\
\hline T. thermophilus $\triangle$ pilA4 & $\mathrm{HB} 27^{\mathrm{EC}} \Delta$ pilA4 & [14] \\
\hline T. thermophilus HB27 $\Delta$ pilA4::hyg & HB27 ${ }^{\mathrm{EC}} \triangle T T C 0858:: h y g$ & [14] \\
\hline T. thermophilus $\mathrm{HB} 27^{\mathrm{H}}$ & $\mathrm{HB} 27^{\mathrm{EC}} \triangle T T C 0313:: h y g$ & {$[14]$} \\
\hline T. thermophilus HB27 gdh::kat & HB27 [ $\triangle T T C 1211:: k a t]$ & [12] \\
\hline T. thermophilus HB27 hepA::pk & HB27 ${ }^{\mathrm{EC}}$ TTC0147::pK18 & This work \\
\hline T. thermophilus HB27 $\Delta$ hepA::kat & $\mathrm{HB} 27^{\mathrm{EC}} \Delta T T C 0147:: k a t$ & This work \\
\hline T. thermophilus HB27 $\Delta$ hepA::hyg & HB27 ${ }^{\mathrm{EC}} \triangle T T C 0147:: h y g$ & This work \\
\hline T. thermophilus HB27 $\triangle$ hepA::kat pilA4 & HB27 ${ }^{\mathrm{EC}} \Delta T T C 0147:: k a t, \Delta$ pilA4 & This work \\
\hline T. thermophilus HB27 hepAYFPph & HB27 ${ }^{\mathrm{EC}}[$ [TTC0147-sYFP:pH118] & This work \\
\hline T. thermophilus HB27 $\Delta$ hepA, $\Delta$ pilA4 $\mathrm{PMH}$ & HB27 ${ }^{\mathrm{EC}} \Delta T T C 0147:: k a t, \Delta p i l A 4[\mathrm{pMH}:: T T C 0147]$ & This work \\
\hline
\end{tabular}




\subsection{Isolation of Mutants}

Mutants were isolated by replacement of the targeted gene by a gene cassette encoding thermostable-resistant to $\mathrm{Km}$ through transformation of the parental strain with the appropriate linear DNA construction featuring upstream and downstream recombination arms [15]. PCR amplification with the oligonucleotides, described in Table 2, was used to obtain the recombination arms. The constructed plasmids are described in Table 3.

Table 2. Oligonucleotides used in this work. In capital letters, the annealing sequence and, underlined, the cloning restriction site employed.

\begin{tabular}{|c|c|}
\hline Primer (Use) & Sequence $5^{\prime} \rightarrow 3^{\prime}$ \\
\hline TTC0313dir & CTTTACGAGGCCCTCTTGGAG \\
\hline TTC0313rev & CCACCGCTCGGGGAC \\
\hline AB92 (check pilA4 deletion) & AAATGCTGAAGCTTGGCGGCAAC \\
\hline AB93 (check pilA4 deletion) & AAAAGAATTCGGGAGTTAGGCTTGGGATTGTG \\
\hline AB219 (check hepA deletion) & СTACCTGAAGAACTCCCGGCGCAG \\
\hline AB220 (check hepA deletion) & GTGAAGCGTATCGGCGTGGTCTTG \\
\hline AB221 (insertion hepA) & aaagaattcGAGGTGGCCTACCTCAACCTG \\
\hline AB222 (insertion hepA) & aaactgcagGAGCTCGTCCAGGACGATGAAG \\
\hline AB231 (hepA-YFP fusion) & actagtCCTGAAGAACTCCCGGCGCAG \\
\hline AB232 (hepA-YFP fusion) & 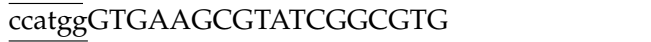 \\
\hline AB249 (deletion hepA) & $\overline{\text { aaagaattcGTAATCTAGGGGCATGGCCTG }}$ \\
\hline AB250 (deletion hepA) & aaatctagaCTTCACCTCGCACCTCCCA \\
\hline AB251 (deletion hepA) & aaatctagaGATGGCCTCGCCATGAAGA \\
\hline AB252 (deletion hepA) & aaactgcagCAGGGGCGAATAC \\
\hline AB247 (overexpression hepA) & aaacatatgGTGAAGCGTATCGGCGTG \\
\hline AB248 (overexpression hepA) & aaaaagcttCTACCCGAAGAACTCCC \\
\hline
\end{tabular}

Table 3. Plasmids employed in this work.

\begin{tabular}{|c|c|c|}
\hline Plasmid & Description/Use & Reference \\
\hline pET28b(+) & Recombinant expression of proteins in E. coli & Novagen \\
\hline pUC19/18 & Cloning vector & [16] \\
\hline pUC19::kat & pUC19 with the thermostable kat resistance gene cassette & This work \\
\hline pUC19::hyg & pUC19 with the Hyg resistance gene cassette & This work \\
\hline pK118 & Suicide vector for T. thermophilus, Thermostable Km resistance & [12] \\
\hline pH118 & Suicide vector for T. thermophilus, Thermostable Hyg resistance & [15] \\
\hline pMK184 & Cloning vector for T. thermophilus. Km resistance & [15] \\
\hline pMH184 & Cloning vector for T. thermophilus. Hyg resistance & [15] \\
\hline pMHPnqosYFP & Expression of sYFP in T. thermophilus & [12] \\
\hline pAB135 & pET28b derivative for overexpression of N-terminal His-tagged HepA & This work \\
\hline pAB207 & pUC18::hepA::kat. For the isolationon of $\Delta$ hepA::kat mutants & This work \\
\hline pAB219 & pH118:hepA::sYFP. pH118 derivative to generate chromosomal fusions of HepA to sYFP & This work \\
\hline pAB175 & Derivative of pMHPnqosYFP for the ectopic expression of the HepA-sYFP fusion in T. thermophilus & This work \\
\hline pAB150 & Plasmid for the isolation of Hyg resistant single insertion hepA mutants & This work \\
\hline pAB151 & Plasmid for the isolation of $\mathrm{Km}$ resistant single insertion hepA mutants & This work \\
\hline pAB141 & Hyg-resistant plasmid for the hepA mutants & This work \\
\hline
\end{tabular}

\subsection{HepA Inmunodetection}

The presence of the HepA protein was detected by Western blot on cell fractions of T. thermophilus cultures by using a rabbit antiserum raised against the purified protein. For this, an exponential culture of T. thermophilus HB8 was harvested, washed in phosphate buffer (50 mM sodium phosphate, $\mathrm{pH} 7$ ), concentrated to $1 / 10$ of the culture volume in the same buffer, and disrupted by sonication ( $4{ }^{\circ} \mathrm{C}$, three pulses of 1 min with 0.5 s cycles, 0.9 intensity, Labsonic, Braun, Goettingen, Germany). Unbroken cells were discarded by centrifugation $(5000 \times g, 5 \mathrm{~min})$, and the soluble fraction was obtained after two consecutive centrifugation steps $(15,000 \times g, 20 \mathrm{~min})$. The particulate fraction, including membranes and cell wall polymers, was re-suspended in the same volume and buffer, and the SDS-soluble protein fraction was subsequently analyzed by PAGE and Western blot with anti-HepA 
antiserum. Goat anti-rabbit antibodies bound to horseradish peroxidase and chemiluminescence were used for detection (ECL, Amersham International, Buckinghamshire, UK).

\subsection{Protein Purification and ATPase Assays}

The gene hepA was cloned into plasmid pET28b, which adds a 6xHistidine tag fused to the N-terminus to generate pAB135. Expression in E. coli BL21 (DE3) cells was induced with $1 \mathrm{mM} \mathrm{IPTG}$ and growth was maintained for $4 \mathrm{~h}$ at $30^{\circ} \mathrm{C}$, after which cell pellets were harvested by centrifugation $\left(23,700 \times g, 20 \mathrm{~min}\right.$ at $\left.4{ }^{\circ} \mathrm{C}\right)$ and broken by a French press (GEA Niro Soavi Homogeneizador Panda Plus 2000, Parma, Italy). After cell disruption and elimination of the insoluble fraction by centrifugation $\left(23,700 \times g, 20 \mathrm{~min}, 4^{\circ} \mathrm{C}\right)$ supernatants were heated at $70{ }^{\circ} \mathrm{C}$ for $30 \mathrm{~min}$ in order to denature thermolabile E. coli proteins, which were then discarded by centrifugation $\left(23,700 \times g, 20 \mathrm{~min}, 4^{\circ} \mathrm{C}\right)$. His-tagged proteins were purified by affinity chromatography on TALON CellThru resin columns following the manufacturer's instructions (Clontech Laboratories, Inc., Palo Alto, CA, USA). Purified proteins were eluted in elution buffer (50 mM phosphate buffer $\mathrm{pH} 7.0,300 \mathrm{mM} \mathrm{NaCl}, 150 \mathrm{mM}$ imidazol) and further dialyzed and concentrated in $25-50 \mathrm{mM}$ Tris- $\mathrm{HCl}$ buffer ( $\mathrm{pH} 7.5)$ using Amicon Ultra concentrator tubes (30 kDa cutoff) (Millipore, Cork, Ireland). Proteins were visualized by SDS-PAGE, and concentrations were determined using the Bio-Rad Protein Assay (Bio-Rad, Hercules, California, USA) following the manufacturer's instructions. Aliquots of the purified proteins were stored at $-20{ }^{\circ} \mathrm{C}$ in $50 \%$ glycerol or kept without glycerol at $4{ }^{\circ} \mathrm{C}$ for immediate biochemical treatment in ATPase assays or transmission electron microscopy (TEM) preparations.

ATPase assays involved screening of ATP hydrolysis using the luciferin-luciferase ATP Bioluminescence Assay Kit CLS II (Roche Diagnostics, Mannheim, Germany), following the manufacturer's indications. End-point kinetic assays were performed by employing different dilutions of the purified enzyme in ATPase activity buffer $\left(5 \mathrm{mM} \mathrm{MgSO}_{4}, 50 \mathrm{mM} \mathrm{NaCl}, 25 \mathrm{mM}\right.$ Tris- $\mathrm{HCl} \mathrm{pH} 7.5$, and $0.1 \mathrm{mM}$ of ATP (Sigma-Aldrich, Saint Louis, MO, USA) for $1 \mathrm{~h}$ at $65^{\circ} \mathrm{C}$. At least four replicates per sample were conducted, including negative controls (protein with no substrate and spontaneous conversion control).

\subsection{Single-Particle Electron Microscopy and Image Processing}

Samples of purified HepA (2-5 mL at $0.3 \mathrm{mg} / \mathrm{mL}$ in Tris-ClH $20 \mathrm{mM} \mathrm{pH} \mathrm{7.5)} \mathrm{pre-incubated}$ with 1-10 mM ATP (30 min, $65^{\circ} \mathrm{C}$ with shaking) were applied to glow-discharged carbon-coated grids for $2 \mathrm{~min}$. Grids were washed twice with water and negatively stained with $2 \%(\mathrm{w} / \mathrm{v})$ aqueous uranyl acetate. Electron microscopy images were recorded on a CCD camera $(4 \mathrm{k} \times 4 \mathrm{k}$ resolution TEMCam-F416, TVIPS, Gauting, Germany) in a JEOL 1010 JEM electron microscope (JEOL, Tokyo, Japan) operating at $80 \mathrm{kV}$. Images were recorded at a $2.44 \AA$ /pixel sampling rate, with an under-focus ranging from 0.7 to $1.5 \mu \mathrm{m}$.

General image processing operations were performed using Xmipp software [17] and graphics were produced by UCSF Chimera [18]. The CTF (contrast transfer function) was corrected with Ctffind3 [19] and images were down-sampled to a factor of 2, with a final sampling ratio of $4.88 \AA$ /pixel. The Xmipp automatic picking routine was used to select 86,639 HerA particles. Images were classified using a reference-free clustering approach with the CL2D program [20] to select a homogeneous population of 86,506 particles. An artificial noise model was used as the starting reference for iterative angular refinement using the EMAN program [21]. The resulting model was selected and refined using the Xmipp iterative projection matching routine [22]. After independent refinement processes, $90 \%$ of particles were included in the final three-dimensional reconstruction with C6 symmetry, and the resolution of the model was determined by the Fourier shell correlation (FSC) criterion between independent half-dataset maps applying a correlation limit of 0.5 .

The Chimera fitting routine was used to dock the HerA atomic model from Sulfolobus solfataricus [6] in the three-dimensional HepA map after initial manual placement. Each protomer of the crystallographic HerA hexamer was fitted in the cryo-EM map as an independent rigid body. 


\subsection{UV and Temperature Resistance Assays}

Resistance against UV radiation and high temperature were measured as the ratio of viable cells after stress with respect to untreated controls. UV treatments involved a $60 \mathrm{~min}$ UV light exposure (Sylvania G8T5, Osram, Munich, Germany, $\lambda=254 \mathrm{~nm}, 10 \mathrm{~cm}$ ) on liquid cultures of $0.5 \mathrm{~mL}$ extended on an empty Petri dish $3 \mathrm{~cm}$ in diameter. Thermal stress tests were carried out on unstirred cultures incubated for $18 \mathrm{~h}$ at $60^{\circ} \mathrm{C}, 70^{\circ} \mathrm{C}$, and $75^{\circ} \mathrm{C}$. Tests were performed in triplicate and the strain used as the wild-type in these analyses was the $\Delta g d h:: k a t$ mutant to discard any role of the $\mathrm{Km}$ resistance on the results.

\subsection{Confocal Microscopy}

Cells transformed with suicide plasmid pAB219 produce a HepA-sGFP fusion from its own promoter in the chromosome. For confocal microscopy analysis the cells were grown at $60{ }^{\circ} \mathrm{C}$ in $\mathrm{TB}$ medium to an $\mathrm{OD}_{600 \mathrm{~nm}}$ of 0.2 before a $4 \mathrm{~mL}$ aliquot was extended in a Petri dish (60 mm of diameter) and irradiated for $15 \mathrm{~min}$ with UV light (Sylvania G8T5, $\lambda=254 \mathrm{~nm}, 10 \mathrm{~cm}$ of distance). The culture was further allowed to grow at $60^{\circ} \mathrm{C}$ for one more hour. When the HepA-sYFP was expressed ectopically from plasmid pAB175, the cells were subjected confocal microscopy in exponential phase $\left(\mathrm{OD}_{600 \mathrm{~nm}}\right.$ of 0.5). For confocal microscopy, around $5 \times 10^{8}$ cells were washed once with PBS buffer [23], fixed for $5 \mathrm{~min}$ with $1.5 \%(\mathrm{w} / \mathrm{v})$ paraformaldehyde, and after centrifugation and re-suspension in PBS, the cells were laid onto microscope slides previously covered with an ultra-thin $0.01 \%$ poly-L-Lysine and topped with Mowiol-treated cover slips. Images of cells were acquired with a LSM 710 confocal laser scanning microscope coupled to a vertical AxioImager M2 (Zeiss, Stockholm, Sweden) and an immersion objective 100X/1.4 oil Plan-Apochromat (Zeiss, Jena, Germany). All photographs were taken under the same settings of excitation/emission of a $514 \mathrm{~nm}$ argon laser. Bright field photos were also taken with Nomarski's optics. Final image design was completed with Image J software (Wayne Rasband, NIH, Bethesda, MD, USA). Duplicates for every sample were prepared as well.

\subsection{Transformation and Transjugation Assays}

Quantitative transformation assays were performed as described [14] using exponential cultures grown at $60^{\circ} \mathrm{C}$ and 15 or $150 \mathrm{ng}$ of genomic or plasmid DNA, respectively. Transformation frequencies were expressed as the ratio of viable cells on selective plates versus viable cells in non-selective medium.

Transjugation experiments were conducted as described [14]. In short, matings involved mixing of the mates in the presence of DNase I (5 units; Roche) of $100 \mu \mathrm{L}$ of saturated cultures of Hygand $\mathrm{Km}$-resistant strains, previously washed in one volume of TB and then resuspended in $10 \mu \mathrm{L}$ of TB containing DNase I ( 5 units; Roche) and plated onto sterile $0.22 \mu \mathrm{m}$ nitrocellulose filters (GSWP, Millipore) on TB agar plates prior to incubation for $4 \mathrm{~h}$ at $60^{\circ} \mathrm{C}$. After incubation, cells were detached from the filters and resuspended in $\mathrm{TB}$, and appropriate serial dilutions were plated onto selective agar plates. Transjugation frequencies were expressed as the number of CFU grown in double-selective media $(\mathrm{Hyg}+\mathrm{Km}$ ) per CFU grown on Hyg-containing agar plates. When matings involved chloramphenicol $(\mathrm{Cm})$-resistant wild-type strains the transjugation frequencies were referred to colonies grown on $\mathrm{Cm}$-containing plates.

Statistical analysis of the transfer frequencies was performed using SPSS ${ }^{\circledR}$ Statistics v.21.0 (SPSS Inc., Chicago, IL, USA; 2008), considered statistically significant for $p$-values $<0.05$. Inferential and comparative assays were performed when necessary and include Student's $t$-tests, Kruskal-Wallis one-way analysis, Wilcoxon tests, and one-way analysis of variance (ANOVA) test, as described [15].

\section{Results}

\subsection{Presence of HerA Homologs in Thermus}

Among the members of the FtsK-HerA familiy of DNA translocases-helicases encoded by Thermus thermophilus HB27, the product of the gene of code TTC0147 shows the highest similarity to the HerA 
helicase of archaea [15]. HepA, the product of this gene, is 576 amino acids long, being conserved at the sequence level among all of the Thermus spp. so far sequenced (Supplementary Materials Figure S1). As in other members of this protein family, HepA includes an HAS barrel domain near its N-terminus and Walker A and Walker B motifs that suggest ATPase activity for this protein.

The genome context of the hepA gene in different Thermus spp. is shown in Figure 1. As its archaeal HerA homologs, the hep $A$ gene is preceded by a gene encoding a putative protein with sequence similarity to nucleases of the archaeal NurA family [24]. However, whereas in most Thermus spp. this NurA homolog is 293 amino acids long, in the HB27 strain the protein appears truncated, with its first 244 amino acids basically identical in sequence to its counterparts in other Thermus spp., and an unrelated eight amino acid extension, making a protein of 251 amino acids (NurA $\Delta C$ ). A detailed comparison revealed that this protein truncation is the consequence of a single nucleotide (cytosine) deletion at position 727 from the start codon of its coding gene. To be sure that this was not a consequence of an error in the published sequence, a whole genome re-sequencing of the HB27 strain was carried out, confirming the deletion in the nurA-like gene in two different stocks of the HB27 strain.

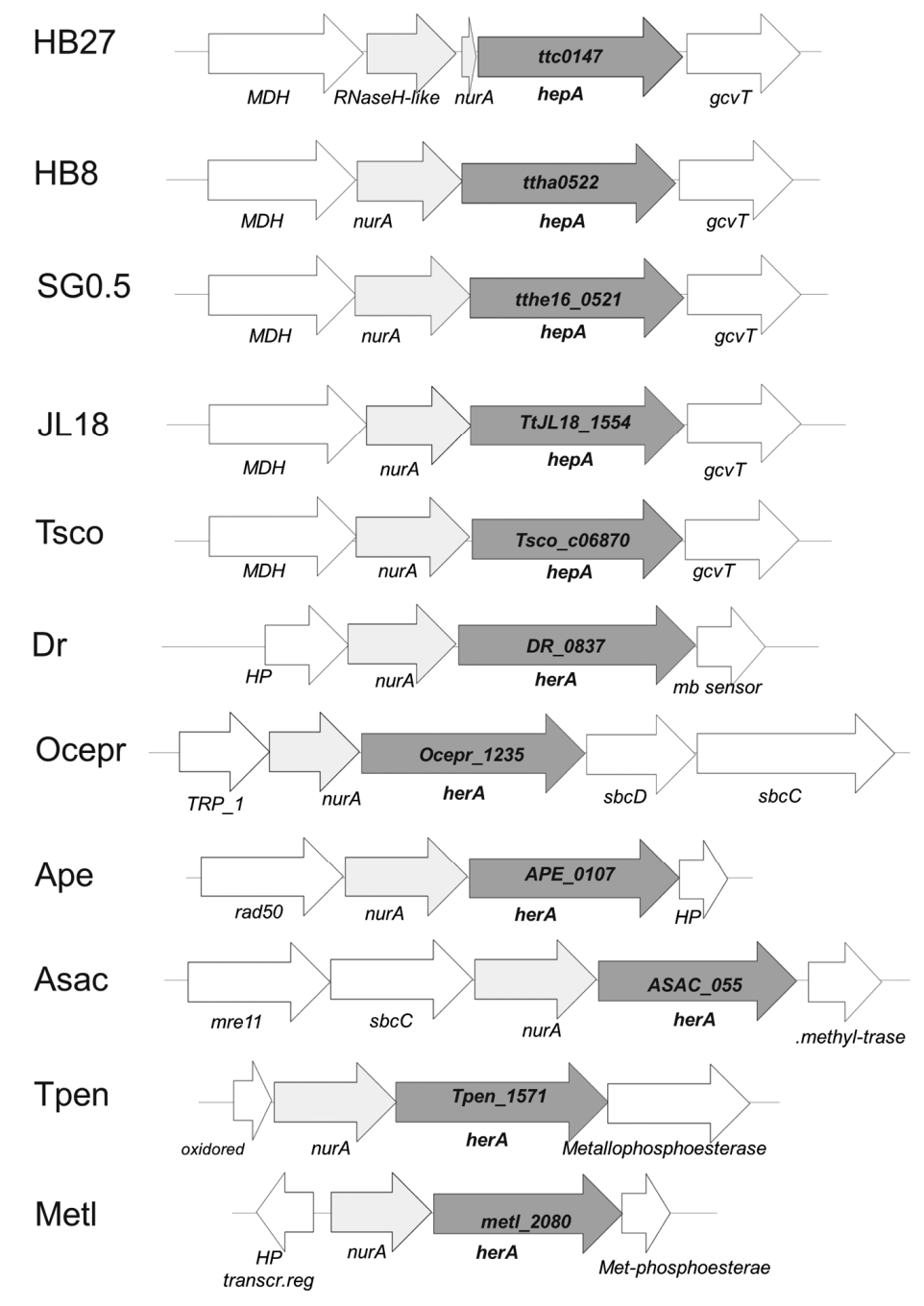

Figure 1. Genomic context of hepA homologs. Synteny of the cluster in which the common homolog of Hep $A$ is found in T. thermophilus HB27 (ttc0147), T. thermophilus HB8 (ttha0522), T. thermophilus SG0.5JP16-17 (tthe16_0521), T. thermophilus JL18 (TtJL18_1554) and T. scotoductus (Tsco_c06870), Deinoccoccus radiodurans (DR_0837), Oceanithermus profundus (Ocepr_1235), and the archaea Aeropyrum pernix (APE_0107), Acidolobus saccharovorans (ASAC_055), Thermofilum pendens (Tpen_1571), and Methanobacteirum lacus (metl_2080). 
The gene context around the nurA-hepA genes has no apparent relation with DNA metabolism in Thermus spp. Actually, a homolog of the malic enzyme (NADP-dependent malate dehydrogenase) is encoded upstream from nurA, whose stop codon is separated only by 4 bp from the ATG start codon of nurA. In strains of Thermus spp. with a complete nurA gene, the stop codon of nurA overlaps the start codon of hepA. This suggests the existence of co-transcription of the malic enzyme gene and the nurA-hep $A$ tandem. On the other hand, $13 \mathrm{bp}$ downstream from hepA a putative glycine cleavage system aminomethyltransferase $\mathrm{T}(\mathrm{gcvT})$ is encoded, which is followed by other genes apparently related to glycine metabolism. This genomic structure is also conserved in other Thermus spp. (Figure 1), supporting that the nurA-hepA gene duet has been acquired in an ancestor of this genus. In agreement to this, the $\mathrm{G}+\mathrm{C}$ content of the nurA-hepA genes seems homogeneous with respect to that of the genome average (69\%). In contrast, in Oceanithermus profundus, another genus of the Thermales order, genes encoding homologues to the bacterial $\mathrm{SbcD}$ and $\mathrm{SbcC}$ proteins, related to archaeal Mre11 and Rad50 proteins, are encoded downstream of hepA, supporting for this organisms a gene architecture and function similar to that shown by the DSB repair system of archaea. Having in mind the higher similarity in protein sequence between the HepA proteins of T. thermophilus and O. profundus $(66 \%$ of identity), compared to that of each of these proteins and any archaeal protein of the HerA family so far sequenced (Sulfolobus islandicus WP_014512739.1 showing the highest identity at 27\%), these data suggest the acquisition of the hepA gene by an ancestor common to both genera followed by the recruitment of $\mathrm{SbcD}$ and $\mathrm{SbcC}$ proteins in O. profundus.

\subsection{Localization of HepA}

In order to associate the HepA protein to a cell fraction, a polyclonal rabbit antiserum was raised against this protein that allowed its identification by Western blot. As shown in Figure 2, a protein of the expected size for HepA $(64 \mathrm{kDa})$ was identified in the soluble fraction, whereas this protein was not detected in the insoluble membranes and cell wall fraction. These data show that HepA is produced as a soluble cytoplasmic protein, in agreement with bioinformatic predictions.

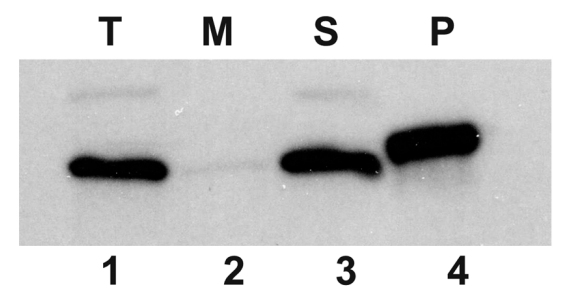

Figure 2. HepA is a cytoplasmic protein. Western blot with an anti-HepA antiserum on whole cells of exponential culture of $T$. thermophilus HB8 (T, lane 1), and its soluble (S, lane 3 ) and membrane fractions (M, lane 2). Purified His-tagged HepA was employed as the control (P, lane 4).

To further localize the protein within the cells, a fusion of HepA to a thermostable fluorescent protein (sYFP) was obtained and expressed both, as a single copy, from its own promoter in the chromosome, and also ectopically from a constitutive promoter in a multicopy plasmid. The expression of the HepA-sYFP fusion from a single copy did not allow the detection of significant fluorescent signals over the background in untreated cells (Figure 3a). However, when these cells were treated with UV (see the Materials and Methods Section) and further allowed to grow for one hour at $60^{\circ} \mathrm{C}$, fluorescent signals were detected in a percentage of the cells (10\%, approximately) (Figure 3b). In these, the fluorescence was extended over the whole cell, likely associated to the nucleoid (Figure 3c). On the other hand, when expressed ectopically from a plasmid, the fluorescence accumulated as very intense dots, most of them of polar localization (Figure 3d). These data support, first, that the protein is expressed at low levels in normal cells and, second, that upon stress the protein is induced by a percentage of the population. Overexpression of the protein fusion from a plasmid could represent a non-physiological situation. 

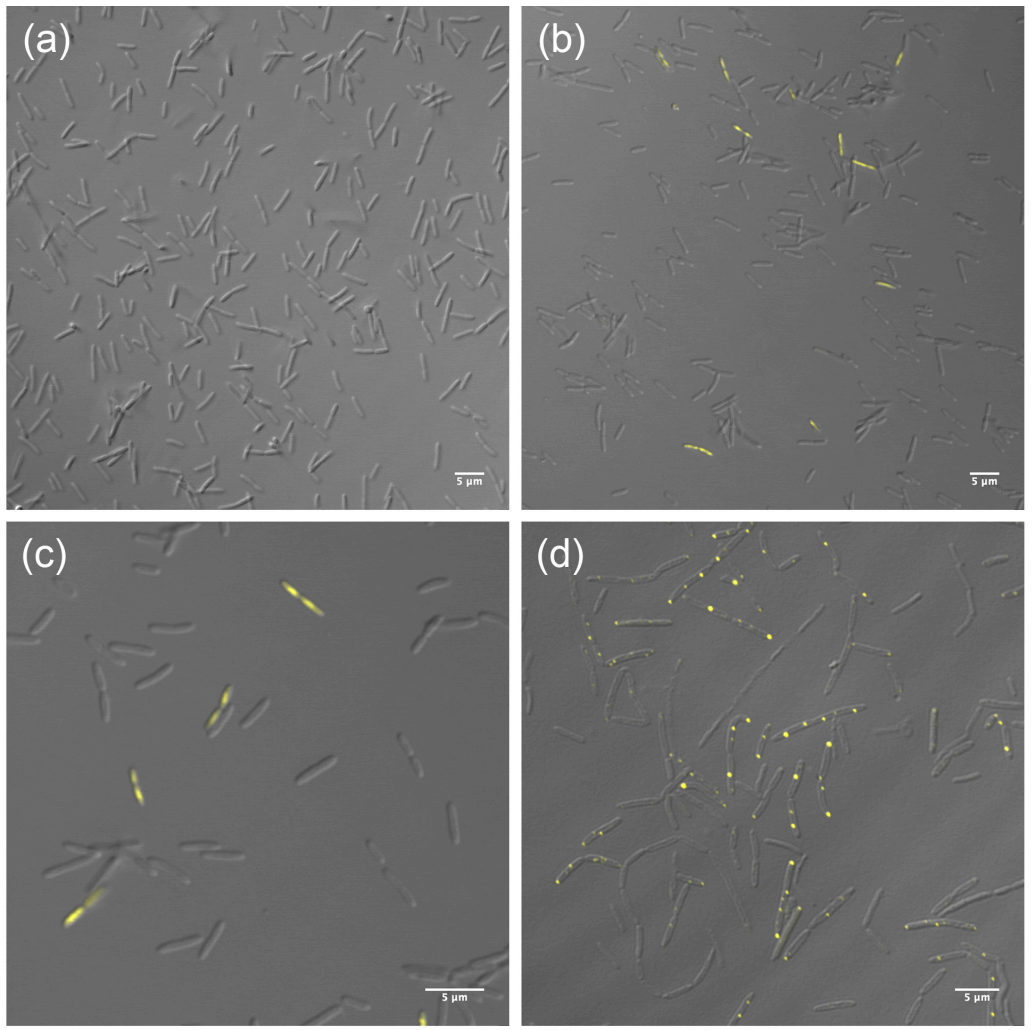

Figure 3. Localization of HepA. HepA-sYFP fusion expressed from a single copy in the chromosome under its natural promoter $(\mathbf{a}-\mathbf{c})$ or ectopically from a multicopy plasmid in a constitutive way (d). Panel (a) corresponds to untreated cells. Panels (b) and (c) correspond to different magnifications of UV-treated cells as described in the Materials and Methods Section.

\subsection{The Role of HepA}

The role of HepA in the physiology of T. thermophilus was investigated through the behavior of deletion mutants. As shown in Figure 4, the $\Delta$ hepA::kat mutant grows at $60{ }^{\circ} \mathrm{C}$ with similar rates compared to a $g d h:: k a t$ mutant used as a wild-type control, but with a small delay in growth initiation. Final cell yields are also similar in both strains under these conditions.

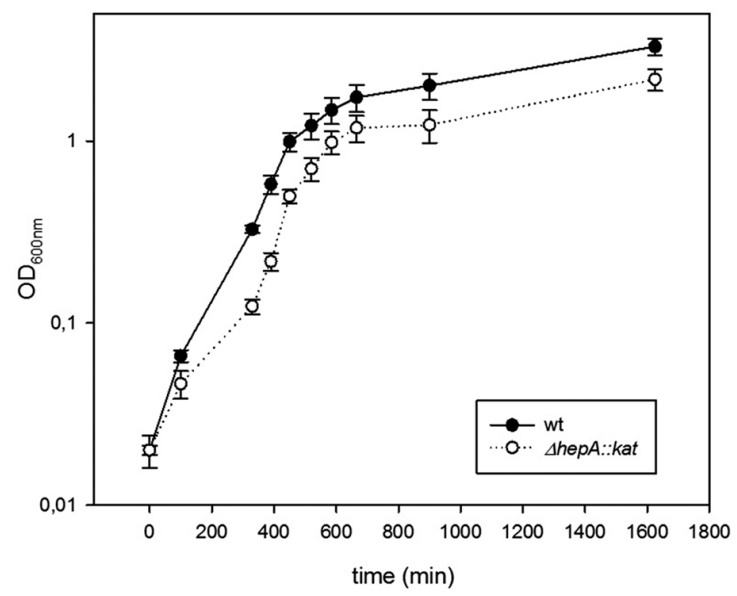

Figure 4. Mutants defective in HepA grow at low temperatures. Growth curves in TB medium at $60{ }^{\circ} \mathrm{C}$ of the wild-type strain (black circles), and its $\Delta$ hepA mutant (empty circle). Error bars represent the deviation of the mean value of three independent samples. 
In order to know if the HepA protein was required for growth at higher temperatures, parallel growth assays starting with the same number of cells from inocula grown at $60^{\circ} \mathrm{C}$ were carried out at $60{ }^{\circ} \mathrm{C}, 70{ }^{\circ} \mathrm{C}$, and $75{ }^{\circ} \mathrm{C}$ with the same two strains, and viable cells were counted after $18 \mathrm{~h}$ of incubation. As shown in Table 4, when the ratio of viable cells for the $\Delta$ hepA::kat vs. that of the $g d h:: k a t$ mutants were compared, similar growth was detected for both strains at $60^{\circ} \mathrm{C}$ (ratio $=1.1 \pm 0.05$ ), as expected from our data of Figure 4. However, this ratio decreased dramatically with the increase in growth temperature, in such a way that it was less than $1: 10$ at $70{ }^{\circ} \mathrm{C}$ and 1:1000 at $75^{\circ} \mathrm{C}$. This means that HepA is required for efficient growth at high temperatures in Thermus thermophilus.

Table 4. Sensitivity to temperature of hepA mutants.

\begin{tabular}{cccc}
\hline Viable CFUs Ratio & $\mathbf{6 0}{ }^{\circ} \mathbf{C}$ & $\mathbf{7 0}^{\circ} \mathbf{C}$ & $\mathbf{7 5}{ }^{\circ} \mathbf{C}$ \\
\hline wt (gdh) & $18.7 \pm 1.7 \times 10^{7}$ & $40.9 \pm 8 \times 10^{7}$ & $16.30 \pm 1 \times 10^{7}$ \\
$\Delta h e p A$ & $20.1 \pm 9.3 \times 10^{7}$ & $33.3 \pm 1 \times 10^{6}$ & $12.8 \pm 3.9 \times 10^{4}$ \\
$\Delta h e p A /$ wt & $1.1 \pm 0.05$ & $8.16 \pm 1.3 \times 10^{-2}$ & $7.8 \pm 0.004 \times 10^{-4}$ \\
\hline
\end{tabular}

The role of HepA in resistance to UV was also studied. For this, the same pair of mutants was treated with UV at different points of their growth curves, and the ratios between viable cells after and before the UV treatment were measured. As shown in Figure 5, wild-type cells (actually the $g d h:: k a t$ mutant) are much more sensitive during exponential growth than cells reaching the stationary phase, in such a way that ratios close to 1:100 were found at late exponential growth, and the resistance increases to almost complete resistance when the cells reached $\mathrm{OD}_{600}$ around 1.5. In the hepA mutant a similar pattern was detected, but showing a much higher sensitivity, in such a way that even cells at $\mathrm{OD}_{600}$ of 1.5 the cells showed a dramatic sensitivity to UV treatment. These data support that HepA is involved in DNA repair processes.

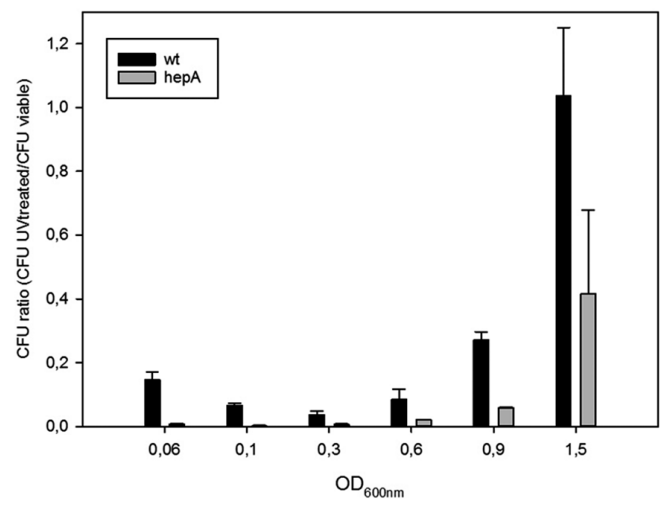

Figure 5. Sensitivity of hepA mutants to UV. Figure shows the ratios between viable cells of UV treated and untreated cells at different cell densities $\left(\mathrm{OD}_{600}\right)$ along the growth curves of T. thermophilus HB27 gdh:kat (wt) and T. thermophilus HB27 $\Delta$ hepA::kat mutant.

\subsection{HepA is Required for DNA Donation in Transjugation}

Thermus thermophilus shows a high capability for horizontal gene transfer due to the concomitant and overlapping concurrence of natural competence and a cell-to-cell transfer mechanism called transjugation [15]. The influence of the HepA protein in these two processes was investigated. As shown in Figure 6a, in the absence of HepA, a significant reduction (around 10-fold) in transformation efficiency was detected with both plasmid and genomic DNA. To analyze its putative relevance in transjugation, and having in mind that in this process both mates can act as donors and recipients (bidirectional) [14], we used a double mutant also affected in pilA, a mutation that makes the cells incapable to act as recipients in the process, but that does not affect its capability for DNA donation [14]. As shown in Figure 6b, crosses between the hepA mutant and a wild-type strain, or 
even a pilA mutant, produced transjugant colonies (bars numbered 1 and 2). By contrast, the double hepA-pilA mutant did not produce transjugants in mating with a wild-type strain (bar number 3), supporting that the hepA mutants are affected by DNA donation. This defect in DNA donation was rescued through the ectopic expression of HepA from a plasmid (bar number 4).
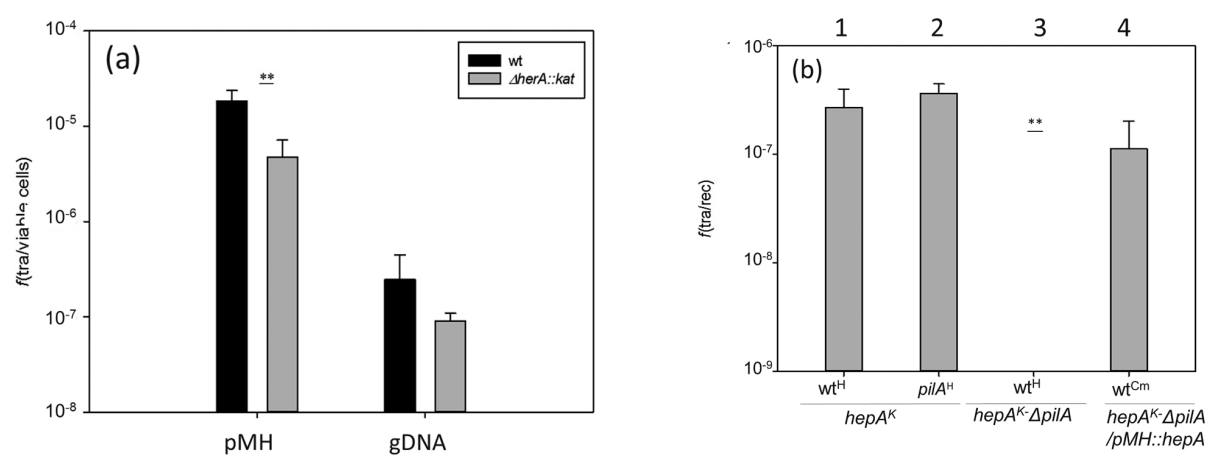

Figure 6. Effects of the absence of HepA in transformation and transjugation. (a) Parallel cultures of T. thermophilus HB27 gdh::kat (wt, black bars) and the $\Delta$ hepA::kat mutant (gray bars) were transformed with $150 \mathrm{ng}$ of plasmid pMH118 or with $15 \mathrm{ng}$ of genomic DNA from an isogenic strain labelled with Hyg resistance in the chromosome; and (b) transjugation assays between the indicated mates. (1) $\Delta$ hepA::kat $\times$ wild-type::hyg; (2) $\Delta$ hepA::kat $\times \Delta p i l A:: h y g$; (3) $\Delta$ hepA::kat- $\Delta$ pilA double mutant $\times$ wild-type::hyg; (4) $\Delta$ hepA::kat- $\Delta$ pilA double mutant containing a plasmid expressing HepA ectopically $\times$ wild-type resistant to $\mathrm{Cm}$. ( $p$-value $<0.005$ is shown as $\left.{ }^{* *}\right)$.

\subsection{HepA Shows Low ATPase Activity}

In order to know if the HepA protein has similar biochemical and structural properties as its archaeal HerA homologs, we purified a recombinant His-tagged protein and assayed its ATPase capability. As shown in Figure 7a, a protein of the expected size was overexpressed in E. coli and purified by affinity chromatography from the soluble fraction. The protein was further shown to have ATPase consumption capability at $65{ }^{\circ} \mathrm{C}$ in a protein concentration-dependent manner (Figure $7 \mathrm{~b}$ ), although the activity detected was low, with only a $25 \%$ of the ATP consumed after $1 \mathrm{~h}$ (around $200 \mathrm{nM}$ of ATP per nM of HepA protein).

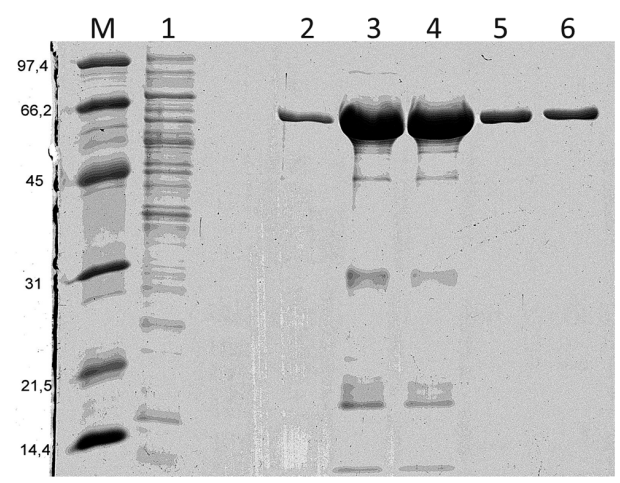

(a)

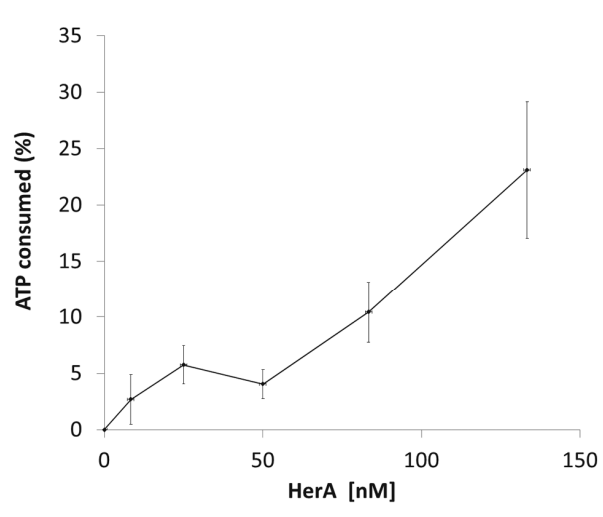

(b)

Figure 7. Purification and ATPase activity of HepA. (a) Coomassie blue-stained SDS-PAGE gel showing purification of HepA as described in materials and methods. (M) Proteins of the indicated size (kDa) used as markers; (1) IMAC column flow-through; (2-6) fractions eluted with imidazole. (b) ATPase activity expressed as the ATP consumed (\%) after incubation for $1 \mathrm{~h}$ at $65{ }^{\circ} \mathrm{C}$ with the indicated concentrations of HepA. The initial concentration of ATP was $10^{-4} \mathrm{M}$. 


\subsection{HepA Is a Complex Hexameric ATPase}

Purified HepA assemblies obtained after incubation with ATP were analyzed by negative stain electron microscopy (Figure 8a). Two-dimensional classification of the images showed that approximately half of the two-dimensional averaged images showed six-fold symmetry (Figure $8 \mathrm{~b}$, left), and 86,506 images were used to generate a three-dimensional reconstruction of the hexameric HepA. The final resolution of the model was estimated to be $16 \AA$. The HepA oligomeric assembly is a complex hexameric ring with two components, a $95 \AA$-long ring with external diameters of 80 and $150 \AA$ on each side (the so-called upper ring), connected by the wider side to a flat ring (the so-called lower ring), $37 \AA$ long with an external diameter of $95 \AA$ (Figure 8c). The upper ring has six $25 \times 15 \AA$ diameter holes on the side. The HepA internal channel has a diameter of 13 and $30 \AA$ at its ends, suggesting that conformational changes are necessary to allow dsDNA passage.

We compared the HepA map with structural homologues, such as the hexameric HerA X-ray structure from S. solfataricus [6] (Figure 8d). Whereas the HerA model (Protein Data Bank (PDB) ID 4D2I) fits well within the upper ring, the lower HepA ring is empty, suggesting major structural differences between HerA and HepA.

(a)

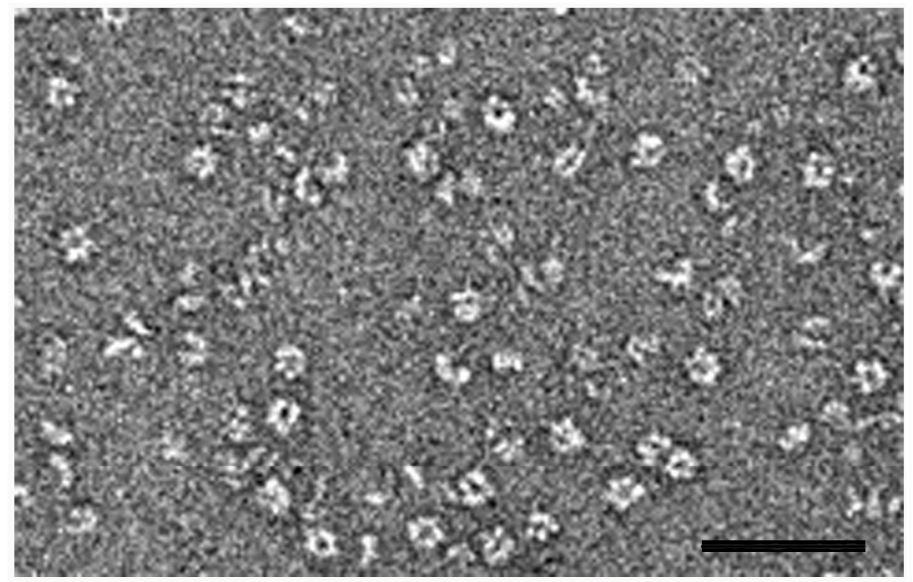

(c)

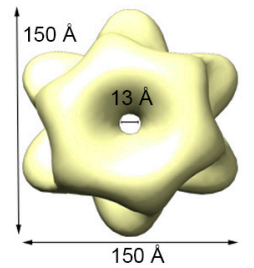

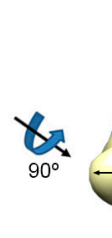

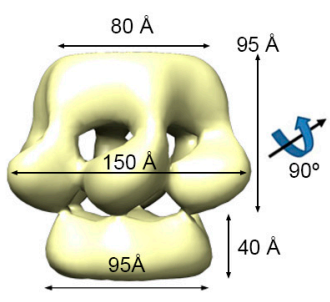

(b)

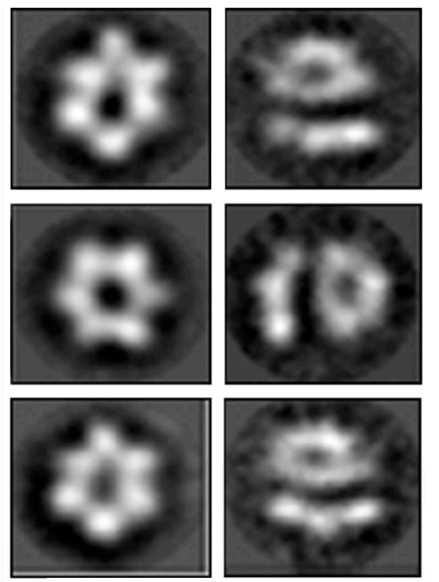

(d)

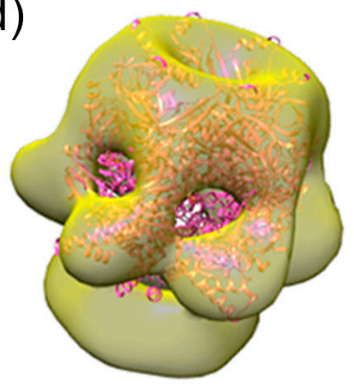

Figure 8. HepA single-particle electron microscopy reconstruction. (a) Representative electron micrograph of a negatively-stained HepA sample. Bar, $50 \mathrm{~nm}$; (b) six two-dimensional averaged classes of the oligomeric HepA; (c) three-dimensional reconstruction of the hexameric HepA with C6 symmetry; and (d) a semitransparent model of the hexameric HepA with a docked atomic model of the hexameric HerA (pink).

\section{Discussion}

Several genes from archaeal origin have been identified in thermophilic bacteria that might be adaptive elements to high temperatures [3], but little experimental data supports such hypothesis. One of these putative adaptive genes from archaeal origin is hepA, encoding a homolog of the HerA, an archaeal helicase, which plays a major role in DSB repair through helping in homologous 
recombination $[25,26]$. Here we show that the product of hepA is actually a hexameric ATPase required for growth at high temperatures and also for survival to DNA damage. However, a number of questions remain unanswered, especially regarding the actual activity of the HepA protein on DNA metabolism and the possible requirement for a nuclease of the NurA family to enhance its activity.

The EM image reconstruction of HepA reveals the classic structure for DNA translocases and helicases, with a central channel of an apparent size of $13 \AA$ which, theoretically, could only accommodate single-stranded DNA. However, in a recent article describing the X-ray structure of HerA from S. solfataricus in complex with DNA, it was shown that the HerA helicase accommodates up to three helix turns of B-dsDNA through a central channel $25 \AA$ wide, pushing it in a mechanism likely dependent of ATP hydrolysis [6]. The fitting of the HerA structure in the EM HepA map indicates that the relatively small size of the central channel in the structure (to passage of dsDNA) was either the consequence of drying and/or negative staining or, alternatively, it could represent an inactive form of the enzyme. Actually, our ATPase activity assays are in agreement with this later hypothesis, as the catalytic activity detected for the hydrolysis of ATP by HepA was very low $\left(0.05 \mathrm{~s}^{-1}\right)$, despite incubation at $65{ }^{\circ} \mathrm{C}$ with this substrate was required for the formation of the hexameric rings.

Our HerA docked model in the HepA map also shows HepA regions at the bottom anneal of the structure that the HerA atomic model lacks (although the last 23 residues at the C-terminal were disordered and did not appear in the HerA structure [6]). Considering that the hexameric HepA structure shows larger cross-section dimensions (50\%) than that described for the HerA crystal, and that both proteins contain a similar number of amino acid residues, it is tempting to speculate that the compacting level of HepA is much lower than that of HerA. Higher resolution analysis will be required in the future to confirm this working hypothesis.

As it happens with HepA, the HerA protein of S. solfataricus, and also that of its homolog in D. radiodurans, shows very low stand-alone ATPase activity. However, this low activity is greatly stimulated by direct interaction with the corresponding nucleases of the NurA family and/or DNA [7] which, for HerA, seems essential in archaea [27]. In all the genomes of Thermus spp. so far available, the HerA homologs (HepA proteins) are preceded by a NurA homolog, supporting that the NurA-HepA tandem is also the active form in Thermus spp. However, in T. thermophilus HB27, the NurA homolog gene preceding hepA appears mutated as a pseudogen [28]. Therefore, either the missing C-terminal domain, absent from this NurA $\Delta \mathrm{C}$ truncated form, is not required for the formation and activity of the NurA-HepA complex, or another NurA homolog substitute for it in this strain. Actually, the HB27 strain contains additional proteins of the NurA family that are absent from its close relative T. thermophilus HB8 [15]. Therefore, the possibility exists of functional replacement of this NurA $\Delta C$ truncated form by another NurA-like protein specific to this strain. In fact, a mutant in this second NurA homolog (code TTC_1878) was as defective in transjugation [15] as the hepA mutant.

Regarding the physiological role played by HepA in T. thermophilus, our data show a significant role in survival to UV treatments, likely acting in a homologous recombination-dependent repair pathway, as described for HerA. Two arguments are in favor of this. First, the protein seems to be overproduced at least by a significant fraction of cells following UV treatment (Figure 3b). Second, the protective role of HepA seems more relevant in cells growing exponentially (Figure 5), where the higher copy number of the chromosome makes homologous recombination more relevant as a repair mechanism than in the stationary phase, where single, or a much limited copy number of the chromosome, are present.

The dramatic effect of the absence of HepA in the ability of the cells to grow at high temperature was unexpected, having in mind that growth at $60^{\circ} \mathrm{C}$ was similar to that of a wild-type strain (also labeled with a $\mathrm{Km}$ marker for comparison). Actually, these results were somehow similar to that shown for recA mutants of $T$. thermophilus, where growth above $60^{\circ} \mathrm{C}$ severely affected the viability and, especially, the fidelity of replication, leading to some class of catastrophic mutagenesis in the cells [29]. The possibility exists that growth at high temperatures could increase the chances for DSB 
during replication and that the role of HepA could, in this sense, be related to that of HerA. However, the requirement for HepA in additional unknown DNA repair mechanisms cannot be discarded.

Regarding the putative role of HepA in transformation, it seems clear that integration of a genomic marker when the incoming t-DNA is lineal depends on double homologous recombination with the chromosome, and in this context a decrease of about one order of magnitude in transformation efficiency of the hepA mutant with respect to a wild-type is also in agreement with a role for HepA in the recombination process. More difficult to explain is the role of HepA in transformation with a replicative plasmid, for which a decrease of an order of magnitude in efficiency was also observed in the hepA mutant. It could be speculated to be a requirement of recombination during the transformation process, even with a plasmid, but this has not been previously described. Alternatively, the transformation process could be defective just because the bacterium has difficulties for growth or because plasmid replication is somehow affected. Whatever the explanation of this defective transformation could be, no supportive data exist to favor any of them.

Transjugation is a process recently described in which a donor T. thermophilus cell donates DNA to a recipient cell which actively import the DNA through its competence apparatus [15]. In this process, the HepA protein seems to be an absolute requirement for DNA donation, as a mutant defective in pilA (unable to act as a recipient) in combination with a hepA mutation, cannot donate DNA to a wild-type strain (Figure 6). The transjugation process, itself, is actually a class of generalized conjugation as it starts simultaneously at several points in the chromosome of the donor cell [14]. We speculate that acting as a DNA donor requires multiple cuts along its chromosome to generate DNA fragments appropriate for donation. The presence of multiple copies of the chromosome [30] would allow the donor to maintain its genetic stability by homologous recombination-mediated DNA repair, a process in which the HepA protein could be an absolute requirement.

Independently of the actual molecular mechanism of DNA repair in which HepA could be involved, the fact is that its absence makes the cells more sensitive to UV and limits the growth temperature at which the strain can grow, supporting that its acquisition from a thermophilic archaea could have helped this genus to adapt to new high-temperature environments. In this scenario, it is of note that the clusters of genes in which the nurA-hepA duet is integrated is fully conserved in all of the genomes of Thermus spp. so far analyzed, and different from that of its clade mate genus Deinococcus. Therefore, our data point to independent acquisition of this nurA-hepA gene tandem in both genus.

\section{Conclusions}

Transfer of DNA has been detected in all three domains of life, making an intense impact in the roots of the phylogenetic tree, grounded among thermophiles. Indeed, comparative analysis of whole genome sequences have unveiled that many genes among thermophilic genomes have been acquired by HGT from external sources, principally thermophilic Archaea, likely helping these organisms to adapt to extreme temperatures. One of these genes of archaeal origin that have likely contributed to thermal adaptation upon acquisition by an ancestor of the genus Thermus is herA, which in Atchaea encodes a helicase implicated in double strand DNA breaks repair mechanism involving recombination. The role of its homologue in Thermus spp., named as HepA, has been analysed showing to be an hexameric cup-like structure with low ATPase activity. Its mutation produces a phase-growth dependent temperature and UV sensitive phenotype, compatible with a role in DNA repair required for high temperature growth. Further studies are needed to examine the complex NurA-HerA in DNA repair systems and DNA transfer.

Supplementary Materials: The following are available online at www.mdpi.com/2073-4425/8/5/130/s1. Figure S1: Sequence alignments of HepA homologs.

Acknowledgments: This work was supported by grants BIO2016-77031-R to José Berenguer and BFU2014-55475-R to José R. Castón from the Spanish Ministry of Economy and Competitiveness, S2013/MIT-2807 to José R. Castón from the Comunidad Autónoma de Madrid, and grants no. 324439 and no. 685474 from the FP7-PEOPLE-2012-IAPP and the H2020 Research and Innovation Program, respectively, of the European Union. 
An institutional grant from Fundación Ramón Areces to the CBMSO (Centro de Biología Molecular Severo Ochoa) is also acknowledged. Fellowships from the Spanish Ministry of Education to Alba Blesa and Ignacio Baquedano and La Caixa Foundation International Fellowship Program (La Caixa/CNB) to Carlos P. Mata, respectively, are also acknowledged.

Author Contributions: Alba Blesa, José Berenguer, and José R. Castón conceived and designed the experiments; Alba Blesa, Nieves G. Quintáns, and Carlos P. Mata performed most of the experiments; Ignacio Baquedado contributed with ATPases assays; and José Berenguer wrote the paper.

Conflicts of Interest: The authors declare no conflict of interest. The founding sponsors had no role in the design of the study; in the collection, analyses, or interpretation of data; in the writing of the manuscript, and in the decision to publish the results.

\section{References}

1. Wu, D.; Hugenholtz, P.; Mavromatis, K.; Pukall, R.; Dalin, E.; Ivanova, N.N.; Kunin, V.; Goodwin, L.; Wu, M.; Tindall, B.J.; et al. A phylogeny-driven genomic encyclopaedia of bacteria and archaea. Nature 2009, 462, 1056-1060. [CrossRef] [PubMed]

2. Hug, L.A.; Baker, B.J.; Anantharaman, K.; Brown, C.T.; Probst, A.J.; Castelle, C.J.; Butterfield, C.N.; Hernsdorf, A.W.; Amano, Y.; Ise, K.; et al. A new view of the tree of life. Nat. Microbiol. 2016, 1, 16048. [CrossRef] [PubMed]

3. Omelchenko, M.V.; Wolf, Y.I.; Gaidamakova, E.K.; Matrosova, V.Y.; Vasilenko, A.; Zhai, M.; Daly, M.J.; Koonin, E.V.; Makarova, K.S. Comparative genomics of thermus thermophilus and deinococcus radiodurans: Divergent routes of adaptation to thermophily and radiation resistance. BMC Evol. Biol. 2005, 5, 57. [CrossRef] [PubMed]

4. Bruggemann, H.; Chen, C. Comparative genomics of Thermus thermophilus: Plasticity of the megaplasmid and its contribution to a thermophilic lifestyle. J. Biotechnol. 2006, 124, 654-661. [CrossRef] [PubMed]

5. Iyer, L.M.; Makarova, K.S.; Koonin, E.V.; Aravind, L. Comparative genomics of the ftsk-HerA superfamily of pumping atpases: Implications for the origins of chromosome segregation, cell division and viral capsid packaging. Nucleic Acids Res. 2004, 32, 5260-5279. [CrossRef] [PubMed]

6. Rzechorzek, N.J.; Blackwood, J.K.; Bray, S.M.; Maman, J.D.; Pellegrini, L.; Robinson, N.P. Structure of the hexameric HerA ATPase reveals a mechanism of translocation-coupled DNA-end processing in archaea. Nat. Commun. 2014, 5. [CrossRef] [PubMed]

7. Cheng, K.; Chen, X.; Xu, G.; Wang, L.; Xu, H.; Yang, S.; Zhao, Y.; Hua, Y. Biochemical and functional characterization of the NurA-HerA complex from Deinococcus radiodurans. J. Bacteriol. 2015, 197, 2048-2061. [CrossRef] [PubMed]

8. Klostermeier, D. Rearranging RNA structures at $75^{\circ} \mathrm{C}$ ? Toward the molecular mechanism and physiological function of the thermus thermophilus dead-box helicase HerA. Biopolymers 2013, 99, 1137-1146. [PubMed]

9. Ramirez-Arcos, S.; Fernandez-Herrero, L.A.; Berenguer, J. A thermophilic nitrate reductase is responsible for the strain specific anaerobic growth of Thermus thermophilus HB8. Biochim. Biophys. Acta 1998, 1396, 215-227. [CrossRef]

10. Hanahan, D. Studies on transformation of Escherichia coli with plasmids. J. Mol. Biol. 1983, 166, 557-580. [CrossRef]

11. Rosenberg, A.H.; Lade, B.N.; Dao-shan, C.; Lin, S.-W.; Dunn, J.J.; Studier, F.W. Vectors for selective expression of cloned DNAs by T7 RNApolymerase. Gene 1987, 56, 125-135. [CrossRef]

12. Cava, F.; Zafra, O.; Magalon, A.; Blasco, F.; Berenguer, J. A new type of NADH dehydrogenase specific for nitrate respiration in the extreme thermophile Thermus thermophilus. J. Biol. Chem. 2004, 279, 45369-45378. [CrossRef] [PubMed]

13. Swarts, D.C.J.; Matthijs, M.; Westra, E.R.; Zhu, Y.; Janssen, J.H.; Snijders, A.P.; Wang, Y.; Patel, D.J.; Berenguer, J.; Brouns, S.J.; et al. DNA-guided DNA interference by a prokaryotic arognaute. Nature 2014, 507, 258-261. [CrossRef] [PubMed]

14. Blesa, A.; César, C.E.; Averhoff, B.; Berenguer, J. Non canonical cell-to-cell DNA transfer in Thermus spp. Is insensitive to argonaute-mediated interference. J. Bacteriol. 2014. [CrossRef]

15. Blesa, A.; Baquedano, I.; Quintáns, N.G.; Mata, C.P.; Castón, J.R.; Berenguer, J. The transjugation machinery of Thermus thermophilus: Identification of TdtA, an ATPase involved in DNA donation. PLoS Genet. 2017, 13, e1006669. [CrossRef] [PubMed] 
16. Vieira, J.; Messing, J. The pUC plasmids, an m13mp7-derived system for insertion mutagenesis and sequencing with synthetic universal primers. Gene 1982, 19, 259-268. [CrossRef]

17. Marabini, R.; Masegosa, I.M.; San Martin, M.C.; Marco, S.; Fernandez, J.J.; de la Fraga, L.G.; Vaquerizo, C.; Carazo, J.M. Xmipp: An image processing package for electron microscopy. J. Struct. Biol. 1996, 116, 237-240. [CrossRef] [PubMed]

18. Pettersen, E.F.; Goddard, T.D.; Huang, C.C.; Couch, G.S.; Greenblatt, D.M.; Meng, E.C.; Ferrin, T.E. UCSF chimera-A visualization system for exploratory research and analysis. J. Comput. Chem. 2004, 25, 1605-1612. [CrossRef] [PubMed]

19. Mindell, J.A.; Grigorieff, N. Accurate determination of local defocus and specimen tilt in electron microscopy. J. Struct. Biol. 2003, 142, 334-347. [CrossRef]

20. Sorzano, C.O.; Bilbao-Castro, J.R.; Shkolnisky, Y.; Alcorlo, M.; Melero, R.; Caffarena-Fernandez, G.; Li, M.; $\mathrm{Xu}$, G.; Marabini, R.; Carazo, J.M. A clustering approach to multireference alignment of single-particle projections in electron microscopy. J. Struct. Biol. 2010, 171, 197-206. [CrossRef] [PubMed]

21. Ludtke, S.J.; Baldwin, P.R.; Chiu, W. Eman: Semiautomated software for high-resolution single-particle reconstructions. J. Struct. Biol. 1999, 128, 82-97. [CrossRef] [PubMed]

22. Scheres, S.H.; Nunez-Ramirez, R.; Sorzano, C.O.; Carazo, J.M.; Marabini, R. Image processing for electron microscopy single-particle analysis using Xmipp. Nat. Protoc. 2008, 3, 977-990. [CrossRef] [PubMed]

23. Phosphate-buffered saline (PBS). Available online: http://cshprotocols.cshlp.org/content/2006/1/pdb. rec8247 (accessed on 26 April 2017).

24. Constantinesco, F.; Forterre, P.; Koonin, E.V.; Aravind, L.; Elie, C. A bipolar DNA helicase gene, herA, clusters with rad50, mre11 and nurA genes in thermophilic archaea. Nucleic Acids Res. 2004, 32, 1439-1447. [CrossRef] [PubMed]

25. Hopkins, B.B.; Paull, T.T. The p. Furiosus mre11/rad50 complex promotes $5^{\prime}$ strand resection at a DNA double-strand break. Cell 2008, 135, 250-260. [CrossRef] [PubMed]

26. Chae, J.; Kim, Y.C.; Cho, Y. Crystal structure of the NurA-dAMP-Mn ${ }^{2+}$ complex. Nucleic Acids Res. 2012, 40, 2258-2270. [CrossRef] [PubMed]

27. Zhang, C.; Tian, B.; Li, S.; Ao, X.; Dalgaard, K.; Gokce, S.; Liang, Y.; She, Q. Genetic manipulation in Sulfolobus islandicus and functional analysis of DNA repair genes. Biochem. Soc. Trans. 2013, 41, 405-410. [CrossRef] [PubMed]

28. Henne, A.; Bruggemann, H.; Raasch, C.; Wiezer, A.; Hartsch, T.; Liesegang, H.; Johann, A.; Lienard, T.; Gohl, O.; Martinez-Arias, R.; et al. The genome sequence of the extreme thermophile Thermus thermophilus. Nat. Biotechnol. 2004, 22, 547-553. [CrossRef] [PubMed]

29. Castan, P.; Casares, L.; Barbe, J.; Berenguer, J. Temperature-dependent hypermutational phenotype in recA mutants of Thermus thermophilus HB27. J. Bacteriol. 2003, 185, 4901-4907. [CrossRef] [PubMed]

30. Ohtani, N.; Tomita, M.; Itaya, M. An extreme thermophile, Thermus thermophilus, is a polyploid bacterium. J. Bacteriol. 2010, 192, 5499-5505. [CrossRef] [PubMed]

(C) 2017 by the authors. Licensee MDPI, Basel, Switzerland. This article is an open access article distributed under the terms and conditions of the Creative Commons Attribution (CC BY) license (http:/ / creativecommons.org/licenses/by/4.0/). 